\title{
ETERNAL $m$-SECURITY BONDAGE NUMBERS IN GRAPHS
}

\author{
HAMideh ARAM \\ Department of Mathematics \\ Gareziaeddin Center, Khoy Branch \\ Islamic Azad University, Khoy, Iran \\ e-mail: hamideh.aram@gmail.com \\ MARYAM ATAPOUR \\ Department of Mathematics \\ Faculty of Basic Sciences \\ University of Bonab, Bonab, I.R. Iran \\ e-mail: m.atapour@bonabu.ac.ir \\ AND \\ Seyed Mahmoud Sheikholeslami \\ Department of Mathematics \\ Azarbaijan Shahid Madani University \\ Tabriz, I.R. Iran \\ e-mail: s.m.sheikholeslami@azaruniv.edu
}

\begin{abstract}
An eternal $m$-secure set of a graph $G=(V, E)$ is a set $S_{0} \subseteq V$ that can defend against any sequence of single-vertex attacks by means of multiple guard shifts along the edges of $G$. The eternal $m$-security number $\sigma_{m}(G)$ is the minimum cardinality of an eternal $m$-secure set in $G$. The eternal $m$ security bondage number $b_{\sigma_{m}}(G)$ of a graph $G$ is the minimum cardinality of a set of edges of $G$ whose removal from $G$ increases the eternal $m$-security number of $G$. In this paper, we study properties of the eternal $m$-security bondage number. In particular, we present some upper bounds on the eternal $m$-security bondage number in terms of eternal $m$-security number and edge connectivity number, and we show that the eternal $m$-security bondage number of trees is at most 2 and we classify all trees attaining this bound.
\end{abstract}

Keywords: eternal $m$-secure set, eternal $m$-security number, eternal $m$ security bondage number.

2010 Mathematics Subject Classification: 05C69. 


\section{REFERENCES}

[1] A.P. Burger, E.J. Cockayne, W.R. Gröndlingh, C.M. Mynhardt, J.H. van Vuuren and W. Winterbach, Infinite order domination in graphs, J. Combin. Math. Combin. Comput. 50 (2004) 179-194.

[2] J.F. Fink, M.S. Jacobson, L.F. Kinch and J. Roberts, The bondage number of a graph, Discrete Math. 86 (1990) 47-58. doi:10.1016/0012-365X(90)90348-L

[3] W. Goddard, S.M. Hedetniemi and S.T. Hedetniemi, Eternal security in graphs, J. Combin. Math. Combin. Comput. 52 (2005) 160-180.

[4] B.L. Hartnell and D.F. Rall, Bounds on the bondage number of a graph, Discrete Math. 128 (1994) 173-177.

doi:10.1016/0012-365X(94)90111-2

[5] T.W. Haynes, S.T. Hedetniemi and P.J. Slater, Fundamentals of Domination in graphs (New York, Marcel Dekker, Inc., 1998).

[6] J. Huang and J. Ming Xu, The bondage numbers and efficient dominations of vertextransitive graphs, Discrete Math. 308 (2008) 571-582. doi:10.1016/j.disc.2007.03.027

[7] A. Meir and J.W. Moon, Relations between packing and covering numbers of a tree, Pacific J. Math. 61 (1975) 225-233.

doi:10.2140/pjm.1975.61.225

[8] U. Teschner, The bondage number of a graph $G$ can be much greater than $\Delta(G)$, Ars Combin. 43 (1996) 81-87.

[9] U. Teschner, New results about the bondage number of a graph, Discrete Math. 171 (1997) 249-259. doi:10.1016/S0012-365X(96)00007-6

[10] U. Teschner, A counterexample to a conjecture on the bondage number of a graph, Discrete Math. 122 (1993) 393-395. doi:10.1016/0012-365X(93)90317-M

[11] D.B. West, Introduction to Graph Theory (Prentice-Hall, Inc., 2000).

[12] Jun-Ming Xu, On bondage numbers of graphs: a survey with some comments, Int. J. Combin. 2013, article ID 595210, 34 pages. doi:10.1155/2013/595210

Received 12 September 2016

Revised 3 April 2017

Accepted 3 April 2017 